\title{
The Raspberry Pi as a Computer Substitute at Elementary Schools in Devel- oping Countries: A Pilot Experiment in Ecuador
}

\author{
Alfredo Nuñez-Unda ${ }^{1, \star}$, Angelo Vera ${ }^{1, \star \star}$, Lidice Haz ${ }^{1, \star \star \star}$, Viviana Pinos ${ }^{1, \star \star \star \star}$, Roberto Zurita ${ }^{1, \dagger}$, and Silvia \\ Medina ${ }^{1, \ddagger}$ \\ ${ }^{1}$ Universidad de Guayaquil, Guayaquil, Ecuador
}

\begin{abstract}
One of the main challenges of developing countries is to shorten the digital divide that exists with developed countries and countries in transition. The government of Ecuador through its National Plan for Technologies and Telecommunications (Plan Nacional de Telecomunicaciones y Tecnologías), has as a goal to give universal access to Technologies of Information and Communication (TICs) to its entire citizens. One of its projects is to assure connectivity and infrastructure in schools. This paper proposes a low-cost open source solution to improve the access to information technology and communication through computers to children of schools in low income areas. The proposed alternative was set out to using the Raspberry Pi $3 \mathrm{~s}$ a substitute of standard computer. Its performance and capabilities were put to test comparing them to standard PC main functions. the pilot experiment was implemented at the "Ciudad de Ariel" elementary school, located on Durán, Ecuador.
\end{abstract}

\section{Introduction}

Over the last two decades, the relevance of TICs in the economical and social development has increased to become part of every economical and production activity. From communication equipment to data analysis, nowadays all human activities go through a technological transformation. The purchase of a pair of shoes now is made from home using a computer, Internet access, and a credit card. Most students don't go to the library to do a research homework, by simply connecting to the web they all have the information needed from different sources. Elite athletes, and sports enthusiasts, don't need a person taking their training results, they now can use electronic widgets that make a thorough record of every variable needed. The list of new technology applications is vast and shows the dimension of its relevance, and its importance in a near and far future.

Developed countries have taken notice of the importance of TICs, and with the years they have invested in infrastructure, research and development, and in education. United States foreseeing the impact of information technologies on the economy, took special attention in investing on $R \& D$ (Research and Development), this strategy gave as result faster, more potent, more efficient, and most important cheaper computer and electronic devices. The drop of costs allowed to all the companies to make

\footnotetext{
^e-mail: alfredo.nunez.u@gmail.com

$\star \star$ e-mail: angelo.vera.rivera@gmail.com

$\star \star \star$ e-mail: victoria.haz@hotmail.com

$\star \star \star \star$ e-mail: viviana.pinosm@ug.edu.ec

†e-mail: roberto.zuritad@ug.edu.ec

\$e-mail: silvia.medinaa@ug.edu.ec
}

constant upgrades, improving their productivity and permitting to take a chance on new technologies [1]. Following this movement, all G7 countries increased their investments on IT devices, accelerating the evolution of technology equipments, making them smaller and more capable. The total investment on IT technology, software, and human capital of G7 countries (including United States) represented more than $60 \%$ of global investment [2].

This is why the developing countries have a crucial job, to try to catch up with the developed countries, specially in matter of information technology. Ir order to shorten the digital divide, Ecuador has outlined the National Plan of Telecommunications and Technologies [3], where it defines four main objectives to reach until the year 2021:

- Complete and promote the deployment of the telecommunications infrastructure.

- Increase the reach of information technology services to the population.

- Assure the use of TIC for the social and economic development of the country.

- Establish the ground bases for the development of local TIC industry at a long term.

One of the main projects involved in objective three is to Ensure the connectivity and technological infrastructure of schools. There are two indexes to evaluate the advance and the fulfillment of the project [3]:

- Percentage of schools connected to the Internet.

- Average number of students per computer. 
At the beginning of the project the values of the indexes chosen were $30 \%$ for the percentage of schools with Internet connection, and 30 is the average number of students per computer. The target at the end of the project is to have a $75 \%$ of schools with Internet connection and an average of 25 students per computer.

With the target for the average number of students per computer still far away from the average from developed countries (between one and three students per computer) a better use of government resources needs to be developed, in order to have more computers with no alteration of the project budget. In the following sections we make a review of the Raspberry PI 3 device, its operation system and basic programs. Later we present a review of projects in different developing countries through the world where a similar approach has been proposed. Later we present our pilot project, a comparison with a standard computer based project, and the results of the tests and first impressions of children that interacted with the computers.

\section{The Raspberry PI}

The Raspberry Pi are single board, high performance computers, developed by the Raspberry Pi Foundation, with its headquarters located at united Kingdom. The main goal of the Raspberry Pi Foundation is to provide lowcost computers with a high performance, and by this helping more people access computing and digital making [4]. The model used for the pilot project is the Raspberry Pi 3 Model B, shown in Fig. 1. The main characteristics are showed in Table 1.

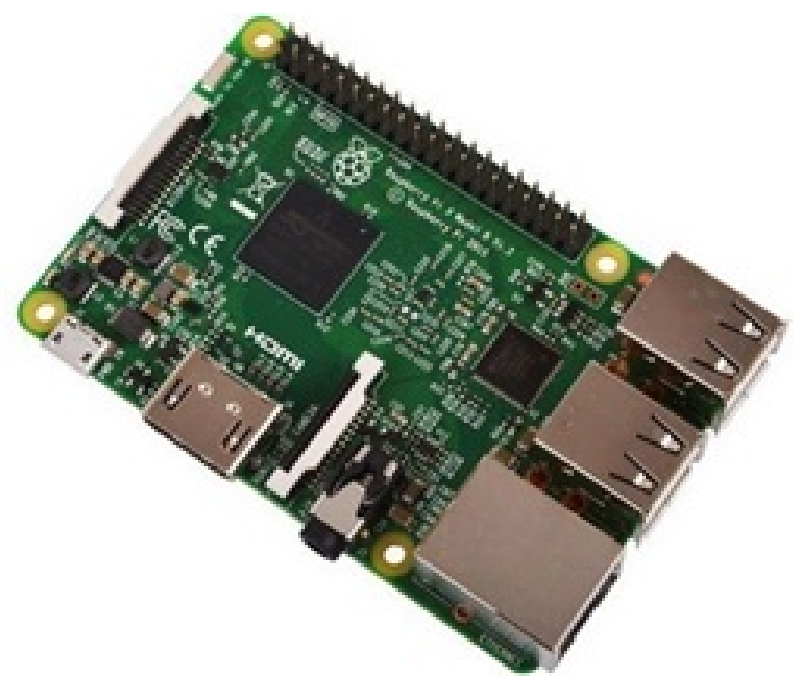

Figure 1. Raspberry Pi 3 Model B

According to our focus group, most children have worked previously with a computer $(81 \%)$. For this reason, and to make the experience as familiar as possible for the students, the desktop of the Raspbian operating system was set to appear just as a regular Windows desktop. Once children have accustomed to the new system, teachers can encourage to the students to go beyond the standard and learn the options an open source operating system have.
Table 1. Raspberry Pi 3 Model B Characteristics

\begin{tabular}{ll}
\hline Components & Description \\
\hline CPU & Quad-core Cortex A7 900MHz \\
Video card & Video core IV double nucleus \\
Network port & 1 Gigabit - Ethernet \\
USB Port & 4 ports USB 2.0 \\
Media ports & 1 pole stereo port \\
I/O port & 40 pin extended GPIO \\
HD media port & 1 port HDMI 1.5 \\
Media I/O interface & 1 CSI camera port \\
& 1 DSI Display port \\
Memory port & Micro SD slot \\
Power outlet & 5Volts at 3mA \\
Wireless Comm port & Bluetooth \\
& WIFI 802.11b/g/n \\
\hline
\end{tabular}

\section{Related Work}

\subsection{One Laptop Per Child (OLPC)}

One Laptop per child (OLPC) is a non-profit organization founded in 2005 by Massachusetts Institute of Technology Professor Nicholas Negroponte. The organization's original vision was to provide a low cost, low power, connected laptop to poor children in order to create education opportunities for them. Initially, the project mobilized a lot of energy and resources around the idea receiving support from United Nations, different governments around the globe, social leaders and technological companies with strong social preoccupations. According to their founders, the project had the potential to eliminate the digital divide between rich and poor children and eventually change the world. ples:

The project centers its vision around five key princi-

- Kids keep the laptops, so they can use then at school or home anytime.

- Focus on early education, the laptop will be used by children between 6 and 12 years old.

- Large number of production, so the product can have a big penetration on communities and everyone gets one.

- Kids have a connection to the Internet, so they can access information and have more learning opportunities.

- Laptop is based on free and open source software, so it can expand to the needs of the child very easily and at low cost.

After some design and production issues that included not properly working technology, quality concerns and final price; the first OLPC prototype was launched in 2007, one year later than the planned date. The prototype was called XO- 1 and despite the original energy and excitement once built upon the project, it had modest production numbers securing only few deals around the world. In the upcoming years, many companies such as INTEL, Motorola and Asus also launched low cost laptops taking the same concept and targeting the same market as OLPC's 
XO-1 but outperforming the device by a long stretch especially in the technological department.

Even though its original promise of delivering a collaborative, joyful and self-empowering machine for hundred dollars or less, the project fell short of its own expectations. Delivery delays, design and quality issues, competition, final price and very modest production numbers diluted the excitement to the point that the original cofounder team with Professor Negroponte at its head, left the organization in 2012. As of today, OLCP still tries to commit to its mission with a whole new team, a new business model, a few spotted successes but overall very poor results.

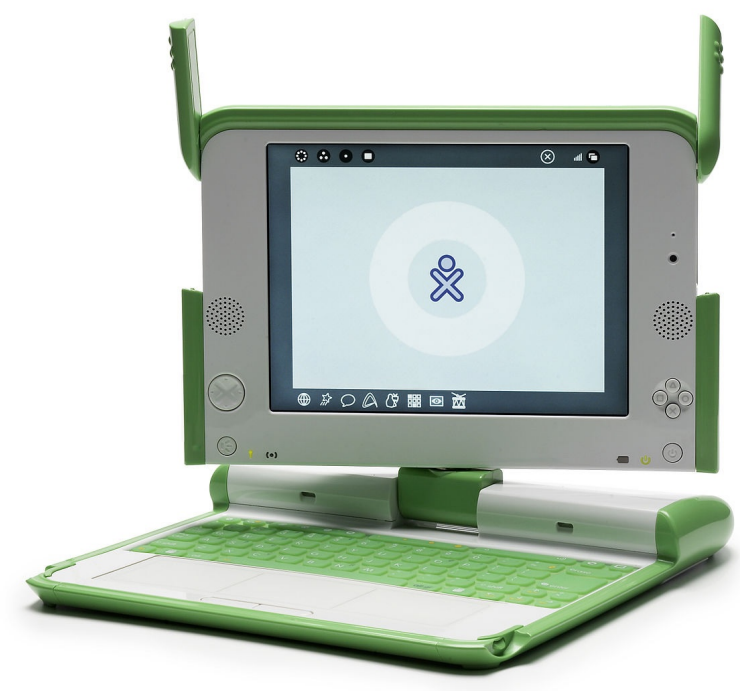

Figure 2. OLPC XO-1 laptop launched in 2007.

\subsection{Raspberry Pi Labs in West Africa}

A not-for-profit project "initiation aux TIC" (IniTIC) initiated the promotion of low cost, low power consumption, low maintenance computer labs in rural schools located in Togo, West Africa. According to DOminique Laloux, one of the project promoters, until $201275 \%$ of teachers of the area had never used a computer [5]. Since then, IniTIC installed 3 computer labs through the rural region of Togo [6]. In Kuma Tokpli in 2012, as shown in Fig. 2. At the Middle School (CEG) of Kuma Adamé in 2014, and at the Collège Polyvalent Saint-Esprit (a M/HS) in Kpalimé in 2016, as shown in Fig. 3.

According to the project group and the experience of getting to work three computer labas, a computer lab equipped with nano-computers (such as the Raspberry Pi) can be an attractive, affordable and a reliable solution to the scarcity of resources in some schools around the world.

\section{Our Pilot Project}

\subsection{Pilot Experiment}

The experiment was implemented at the "Ciudad de Ariel" elementary school. For the task the school facilitated us

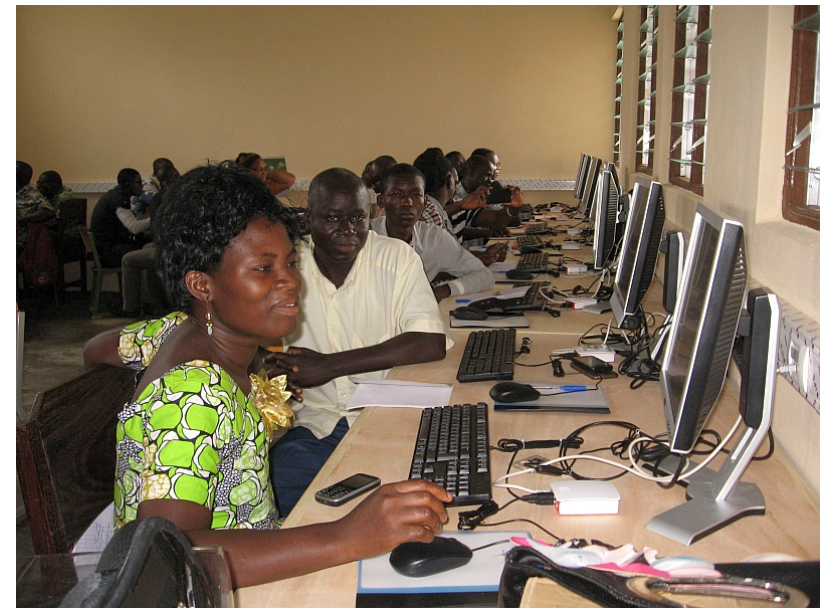

Figure 3. Kpalimé, initial teachers training (summer 2016).

the acces to their only computer lab, provided with 10 standard computers with Windows 7 operating system. The test was made with two Raspberry Pi 3 model B, each one with a monitor, mouse, keyboard, speakers and Internet connection. The first activity was to let children to experiment with the equipment, giving them the liberty to interact according tho their knowledge and their curiosity [7]. Students rapidly adapted their previous knowledge to the options available in the desktop, as shown in fig. 4.

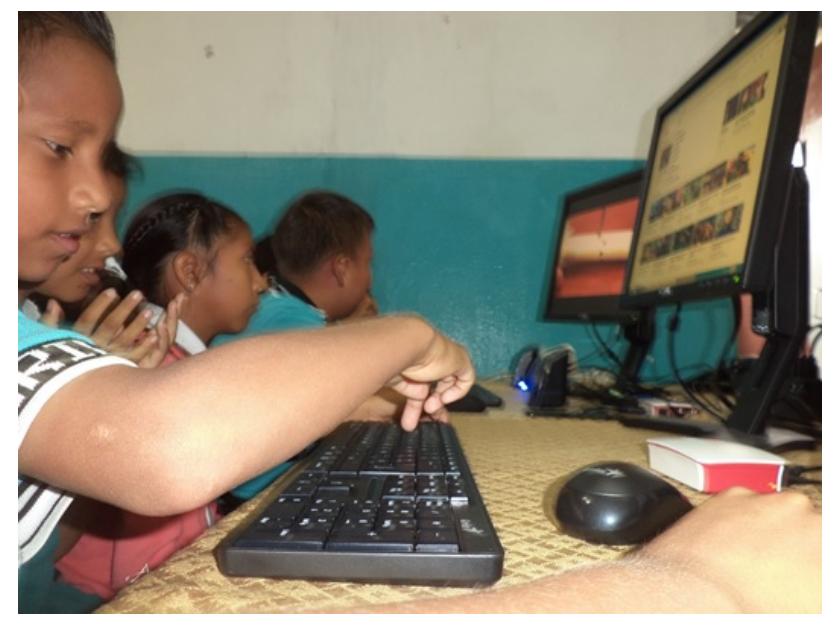

Figure 4. Sudents of "Ciudad de Ariel" Elementary School interacting with the Raspberry Pi nano-computer.

The second activity was to introduce the students to a complete new experience, by teaching them a small programming activity usig the open source tool Scratch. By using this animated and child design learning tool, students of elementary schools can develop logic concepts that are basic for developing coding capabilities. The reactions of the children were more than positive. The curious nature of a child allows them to adapt under new forms of learning. The coding activity was an important experiment, to look how children with none experience on programming activities react, activity cataloged as one of the most important skills facing the future [8]. 


\subsection{Raspberry Pi advantages}

In table 2, a detailed cost comparison between a Raspberry Pi 3 model B nano-computer and a standard computer. Table 3 shows the energy consumption comparison with the same equipments.

Table 2. Comparison between Raspberry Pi 3 and a standard computer.

\begin{tabular}{|c|c|c|c|}
\hline \multicolumn{2}{|c|}{ Raspberry } & \multicolumn{2}{|c|}{ Computer } \\
\hline $\begin{array}{l}\text { Raspberry Pi, } \\
\text { case, micro } \\
\text { SD, fan and } \\
\text { HDMI cable }\end{array}$ & $\$ 108.00$ & $\begin{array}{l}\text { CPU, } \quad 4 \mathrm{~Gb} \\
\text { RAM, } 500 G b \\
\text { HDD }\end{array}$ & $\$ 380.00$ \\
\hline $\begin{array}{l}\text { Keyboard } \\
\text { and wireless } \\
\text { mouse }\end{array}$ & $\$ 20.00$ & $\begin{array}{l}\text { Keyboard and } \\
\text { USB mouse }\end{array}$ & $\$ 17.00$ \\
\hline Speakers & $\$ 7.00$ & Speakers & $\$ 7.00$ \\
\hline $\begin{array}{l}19.5 " \text { Display } \\
\text { monitor }\end{array}$ & $\$ 115.00$ & $\begin{array}{l}19.5 \text { " Display } \\
\text { monitor }\end{array}$ & $\$ 115.00$ \\
\hline $\begin{array}{l}\text { Raspbian OS } \\
\text { and open Of- } \\
\text { fice }\end{array}$ & $\$ 0.00$ & $\begin{array}{l}\text { Standard OS } \\
\text { and standard } \\
\text { office editor } \\
\text { software }\end{array}$ & $\$ 203.12$ \\
\hline Total value & $\$ 250.00$ & Total value & $\$ 722.12$ \\
\hline
\end{tabular}

Table 3. Energy consumption comparison

\begin{tabular}{lrlr}
\hline \multicolumn{2}{c}{ Raspberry } & \multicolumn{2}{c}{ Computer } \\
\hline $\begin{array}{l}8 \text { hours } \\
1 \text { month (8 }\end{array}$ & $\$ 0.045$ & 8 hours & $\$ 0.46$ \\
$\begin{array}{l}\text { hours a day) } \\
1 \text { year }\end{array}$ & $\$ 16.13$ & $\begin{array}{l}1 \text { month } \\
\text { hours a day) } \\
1 \text { year }\end{array}$ & $\$ 13.78$ \\
\hline
\end{tabular}

From this exercise it is clear that the pilot project involves a low cost and efficient approach, where not only its implementation would involve a budget reduction, but also its energy consumption is more effective than other standard options.

\section{Conclusions and Discussion}

It is proven that the Raspberry Pi nano computer is a very good choice to build computer labs with a low cost and efficient approach. The stress tests concluded that the device needs a heat sink and a fan, but once this additional elements are in place, there is no affectation of the computer performance. Also the activities with the students showed an important interest of children in programming activities, and that the process of adaptation is not a problem, children have the ability to adapt to new technologies and novel education methods.

It is highly recommended that this pilot implemented to a large scale, starting with a school, and then to entire regions. Also that all the effort of giving students of low income areas the access to high end computers, it is accompanied with a coding program for elementary school. Programming is cataloged as a essential tool for future jobs.

\section{References}

[1] D.W. Jorgenson, K.J. Stiroh, Brookings papers on economic activity 2000, 125 (2000)

[2] D.W. Jorgenson, Information technology and the G7 economies, Vol. 5 (August, 2004)

[3] M. de Telecomunicaciones y de la Sociedad de la Información, Plan nacional de telecomunicaciones y tecnologias (2016)

[4] T.R.P. Foundation, Raspberry pi official site, https: //www . raspberrypi .org/

[5] T.R.P. Foundation, More raspberry pi labs in west africa, https://www.raspberrypi.org/blog/ pi-based-ict-west-africa/

[6] I. aux TIC, Initic, the project, http: //www .initic. be/p/kuma-project.html

[7] A.F. Ramirez Moreira, Ph.D. thesis, Universidad de Guayaquil Facultad de Ciencias Matemáticas y Físicas Carrera de Ingeniería en Networking y Telecomunicaciones (2018)

[8] M.U. Bers, Coding as a playground: Programming and computational thinking in the early childhood classroom (Routledge, 2017) 